\title{
Suggestive evidence for chromosomal localization of non-coding RNA from imprinted LITI
}

\author{
Kazuhiro Murakami · Mitsuo Oshimura • \\ Hiroyuki Kugoh
}

Received: 1 June 2007/Accepted: 5 September 2007/Published online: 5 October 2007

(C) The Japan Society of Human Genetics and Springer 2007

\begin{abstract}
The non-coding RNA LIT1/KCNQ1OT1, itself the product of an imprinted gene, is involved in cis-limited silencing within an imprinted cluster on human chromosome 11p15.5. Although the locus serves as an imprinting center, the mechanism of transcriptional regulation is not clear. To help understand the function of the LITI noncoding RNA, we used fluorescence in situ hybridization (FISH) to examine the sub-cellular localization of LIT1 RNA molecules. LITI RNA signals were observed in most of the interphase human lymphoblast and fibroblast cells. The RNA also appeared to accumulate on neighboring regions of chromatin containing the SLC22A18/IMPT1 and CDKN1C/p57KIP2 genes, as shown by high-resolution fiber RNA FISH and modified RNA TRAP (tagging and recovery of associated proteins) methods. These results suggest that LITI RNA stably localizes to a specific chromatin region and plays an important role in the transcriptional silencing of the imprinting domain.
\end{abstract}

Keywords Chromosome immunoprecipitation . Fluorescence in situ hybridization - Genomic imprinting . KCNQ1OT1 · LIT1 · Non-coding RNA · RNA TRAP

\section{Introduction}

Genomic imprinting, a phenomenon whereby alleles of some mammalian genes are expressed differentially depending on their parental origin, is critical to

K. Murakami · M. Oshimura $\cdot$ H. Kugoh $(\square)$

Department of Biomedical Science, Graduate School of Medical

Science, Tottori University, 86 Nishicho, Yonago 683-8503,

Japan

e-mail: kugoh@grape.med.tottori-u.ac.jp mammalian development (Delaval and Feil 2004; Surani et al. 1986). Functional analyses have identified several features associated with imprinted genes and regions, including allele-specific DNA methylation, histone modification and asynchronous replication timing. However, the precise molecular mechanism of gene regulation at imprinted loci remains to be clarified.

LIT1/KCNQ1OT1 is expressed exclusively from the paternal allele, an effect that is attributed to the presence of an antisense RNA that recognizes KCNQ1/KvLQT1 (Fig. 1a). The human LITl transcription unit lies within the 11p15.5 imprinted gene cluster; the LIT1 transcription product is reportedly greater than $60 \mathrm{~kb}$ and functions as non-coding RNA (Mitsuya et al. 1999). Aberrations of LITI expression, such as those caused by loss of imprinting (LOI), have been frequently observed in Beckwith-Wiedemann syndrome (BWS) and colorectal cancer (Lee et al. 1999; Tanaka et al. 2001). In addition, loss of maternal-specific methylation at the LITI locus in BWS and several cancers correlates with abnormal imprinting status of CDKNIC (Bliek et al. 2001; Nakano et al. 2006; Scelfo et al. 2002; Schwienbacher et al. 2000). We have recently shown that loss of $\mathrm{CpG}$ and histone $\mathrm{H} 3$ methylation at a differentially methylated region (DMR)-LITI leads to a reduction of $C D K N 1 C$ expression in esophageal cancer (Soejima et al. 2004).

We previously reported that targeted deletion of the paternally DMR at the human LITI locus causes loss of the expression of LITI and the silencing of several genes, including $K C N Q 1, K C N Q 1 D N$ and $C D K N 1 C$ (Horike et al. 2000). Similarly, targeted deletion of the imprinting control center (ICR) located in intron 10 of Kcnql in mice results in the de-repression of six maternally expressed genes, including Phlda2/Tssc3, Slc22a18/Imptl and Cdkn1cl p57kip2 (Fitzpatrick et al. 2002). These protein-coding 


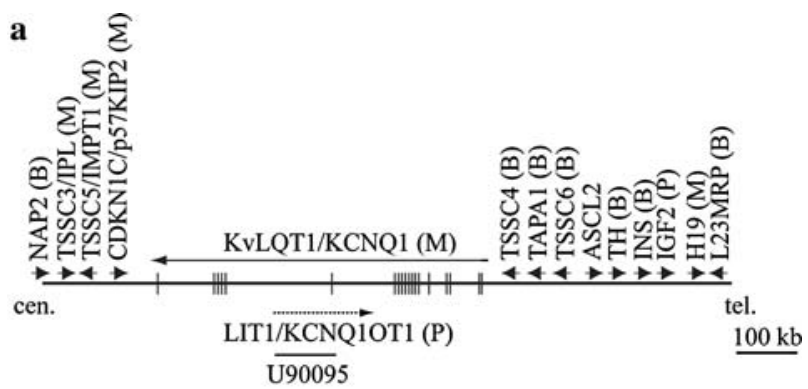

b

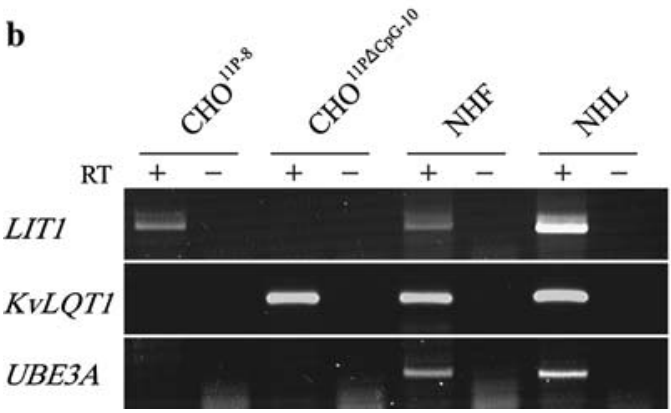

Fig. 1 Schematic representation of the imprinted gene cluster at human chromosome 11p15.5. and expression of LIT1, KCNQ1 and UBE3A in $\mathrm{CHO} 11 \mathrm{P}-8, \mathrm{CHO} 11 \mathrm{P}^{\triangle \mathrm{CpG}}-10$, normal human fibroblasts $(N H F)$ and lymphoblasts $(N H L)$. a The deduced transcriptional orientations are shown with arrowheads and arrows. $P$ Paternally expressed genes, $M$ maternally expressed genes, $B$ biallelically expressed genes, cen. centromere, tel. telomere. b LIT1 was detected by reverse transcriptase(RT)-PCR in CHO11P-8, NHF and NHL, but was absent in $\mathrm{CHO} 11 \mathrm{P}^{\Delta \mathrm{CpG}_{-}} 10$. In contrast, maternally expressed

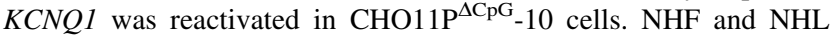
express all three genes, including $U B E 3 A$

genes are all positioned towards the centromere relative to LITI (Fig. 1a). These data suggest that LIT1 is required for silencing of these genes and may contribute in cis to the formation of the imprinting center (IC) that is thought to bring about coordinate imprinting in the $11 \mathrm{p} 15.5$ region. Recent results using an episome-based vector system pointed to the possibility that mouse Litl RNA plays a critical role in silencing at the IC of the imprinted gene cluster and showed that the transcript length is important for the degree of silencing (Kanduri et al. 2006). Another study suggested that full-length Litl RNA is necessary for maintaining the imprinting status through functional analysis of a truncated Litl transcript constructed via insertion of a transcriptional stop signal (Mancini-Dinardo et al. 2006). However, how LITI RNA actually affects transcriptional regulation within the sub-chromosomal domain of these genes remains to be elucidated.

To understand the functional role of the LITI non-coding RNA, we used DNA/RNA fluorescence in situ hybridization (FISH) to examine the sub-cellular localization of LITI RNA molecules (Parra and Windle 1993). We also developed a modified RNA tagging and recovery of associated proteins (TRAP) method to determine the precise region over which LITI RNA spreads (Carter et al. 2002). We report here that LITI RNA stably co-localizes with its own gene region through the cell cycle and accumulates at least on the SLC22A18/IMPTI and CDKNIC/ p57KIP2 regions, which lie outside of the LIT1 RNA transcriptional domain. This provides evidence that LITI RNA may play a significant role in modulating transcription at a specific chromosome domain such as IC.

\section{Materials and methods}

RNA extraction and reverse transcriptase-PCR analysis

Total RNA was prepared using RNeasy columns in accordance with the manufacturer's instructions (Qiagen, Valencia, CA) and was treated with RNase-free DNase I (TaKaRa). First-strand cDNA synthesis was carried out with an oligo $(\mathrm{dT})_{15}$ primer and M-MLV reverse transcriptase (Gibco/BRL, Gaithersburg, MD) in accordance with standard procedures.

Primer sequences and PCR conditions are available upon request. Products were visualized by electrophoresis on $2 \%$ agarose gels.

\section{RNA/DNA fluorescence in situ hybridization}

RNA FISH was carried out as described in a previously published protocol with several modifications (Herzing et al. 2002; Van Raamsdonk and Tilghman 2001). Cells were seeded in in a Lab-Tek chamber slide (Nalge Nunc Int, Rochester, NY) and fixed for $20 \mathrm{~min}$ at room temperature with $4 \%$ paraformaldehyde after treatment with $0.075 M \mathrm{KCl}$. After being washed with phosphate buffered saline (PBS), cells were permeabilized with $0.1 \%$ pepsin in $0.01 \mathrm{M} \mathrm{HCl}$ for $10 \mathrm{~min}$ and post-fixed for $5 \mathrm{~min}$ at room temperature with $1 \%$ paraformaldehyde. Cells were dehydrated through an ethanol series and then air dried at room temperature. We used the U90095 P1-derived artificial chromosome (PAC) genomic probe and the $5^{\prime}-$ LIT1 10-kb genomic probe for LITI RNA FISH, and the cosmid probe for UBE3A RNA FISH. The probes were prepared as follows: labeled with biotin-16-dUTP (Roche, Basel, Switzerland) by nick-translation (Roche), purified by ethanol precipitation, dissolved in $20 \mu \mathrm{l}$ formamide, mixed and denatured. Labeled probes and hybridization solution [bovine serum albumin (Roche):10× SSC:50\% dextran sulfate (Sigma), 1:2:2] were mixed 1:1, dropped onto the slide, covered with Parafilm and incubated at $37^{\circ} \mathrm{C}$ for $15 \mathrm{~h}$ in a humidified chamber.

After hybridization, the slide was washed sequentially at $37^{\circ} \mathrm{C}$ in $50 \%$ formamide $/ 2 \times \mathrm{SSC}, 2 \times \mathrm{SSC}$ and $1 \times \mathrm{SSC}$ for 
5 min each time and once in $4 \times \mathrm{SSC}$ for $5 \mathrm{~min}$; the slide was then incubated in $4 \times$ SSC with $1 \%$ BlockAce (Dainippon Pharmaceutical Co, Osaka, Japan) containing $3 \mu \mathrm{g} / \mathrm{ml}$ fluorescein isothiocyanate (FITC)-avidin (Vector Laboratories, Burlingame, CA) for $60 \mathrm{~min}$ at $37^{\circ} \mathrm{C}$. The slide was then washed sequentially for $5 \mathrm{~min}$ in each of $4 \times$ SSC, $4 \times$ SSC containing $0.05 \%$ Triton $X-100$, and $4 \times$ SSC. The slide was mounted in antifade solution [1\% diazabicyclooctane (Sigma) in glycerol with $10 \%$ PBS] containing $1 \mu \mathrm{g} / \mathrm{ml} \mathrm{4}$ ', 6'-diamidino-2-phenylindole (Sigma) and $1 \mathrm{mg} / \mathrm{ml} p$-phenylenediamine (Sigma). Digital images of RNA signals were acquired with a Nikon fluorescence microscope and CCD camera (Hamamatsu Photonics, Hamamatsu City, Japan).

For DNA FISH, the cover slide was removed in $4 \times$ SSC and the sample treated with $0.1 \mathrm{mg} / \mathrm{ml}$ RNase (Sigma) for $1 \mathrm{~h}$ at $37^{\circ} \mathrm{C}$, denatured with a mixture of $70 \%$ formamide and $2 \times \mathrm{SSC}$ at $72^{\circ} \mathrm{C}$ for $2 \mathrm{~min}$ and finally quenched in icecold $70 \%$ ethanol for $2 \mathrm{~min}$. The sample was dehydrated and hybridized with a digoxigenin-labeled probe following which the slide was washed as above and immersed in a mixture of $1.6 \mu \mathrm{g} / \mathrm{ml}$ anti-digoxigenin-rhodamine (Roche), $4 \times \mathrm{SSC}$ and $1 \%$ BlockAce for $45 \mathrm{~min}$ at $37^{\circ} \mathrm{C}$. After the slide was washed, detection and capture of DNA signals were carried out as described above for RNA FISH. Images of selected RNA and DNA signals were merged and analyzed using ARGUS imaging software (Hamamatsu Photonics).

\section{High-resolution fiber RNA FISH}

Fiber FISH analysis was performed largely as previously described with some modifications (Parra and Windle 1993). Two hundred cells in $10 \mu \mathrm{l}$ PBS were placed on the end of a slide. After drying, $5 \mu \mathrm{l}$ of cell lysis buffer was applied $[0.5 \%$ sodium dodecyl sulphate (SDS) $/ 50 \mathrm{mM}$ EDTA/200 $\mathrm{m} M$ Tris-HCl]. The slide was incubated for $5 \mathrm{~min}$ at room temperature and then placed on an angle to release stretching DNA from interphase cell nuclei. These bundles were dried and fixed for $20 \mathrm{~min}$ at room temperature with $4 \%$ paraformaldehyde and dehydrated through an ethanol series. The LIT1 transcripts were detected by RNA FISH as described above.

\section{Modified RNA TRAP method}

A modified RNA TRAP method was used as follows (Carter et al. 2002). RNA in situ hybridization was first performed; that is, biotin-labeled probes were hybridized to single-strand RNA on chromatin. Then, applying the chromosome immunoprecipitation (ChIP) method, we collected the biotin-labeled probe/single-strand RNA complex and associated chromatin using anti-biotin antibodies. Finally, genomic PCR was carried out to analyze the chromatin region in which the RNA had accumulated.

Cells $\left(5 \times 10^{5}\right)$ were spread on a petri dish for 2 days and then fixed in $1 \%$ formaldehyde for $10 \mathrm{~min}$ at $37^{\circ} \mathrm{C}$. The reaction was stopped by adding $100 \mu 1.5 \mathrm{M}$ glycine for $10 \mathrm{~min}$ at room temperature. After the cells had been washed with PBS, permeabilization and post-fixation were performed as described above and biotin-labeled probe hybridization was carried out in the petri dish. The dish was incubated at $37^{\circ} \mathrm{C}$ for $15 \mathrm{~h}$ in a humidified chamber, and post-hybridization washing were carried out as described above. Cells were scraped from the petri dish and spun down at 10,000 $\mathrm{g}$ for $3 \mathrm{~min}$, resuspended in $300 \mu \mathrm{l}$ of a mixture of $1 \%$ SDS, $10 \mathrm{~m} M$ EDTA, $50 \mathrm{~m} M$ Tris-HCl $(\mathrm{pH} 8.0)$ and $1 \times$ protease inhibitor, and sonicated for $90 \mathrm{~s}$ on ice (nine 10-s bursts with $60 \mathrm{~s}$ between bursts) using a Bronson Sonifire (output 3; duty cycle 40 ). This procedure yielded chromatin fragments that had an average length of $500 \mathrm{bp}$ each. The crude chromatin was centrifuged at $13,000 \mathrm{~g}$ for $10 \mathrm{~min}$, the supernatant containing the soluble chromatin was collected, and $2.7 \mathrm{ml}$ of a mixture of $0.01 \%$ SDS, $1.1 \%$ Triton-X, $1.2 \mathrm{~m} M$ EDTA (pH 8.0), $20 \mathrm{mM}$ Tris- $\mathrm{HCl}(\mathrm{pH} 8.0), 150 \mathrm{mM} \mathrm{NaCl}$, and $1 \times$ protease inhibitor was added; $10 \%$ of the soluble chromatin was set aside as the input and the suspension was pre-cleared with $60 \mu \mathrm{l}$ of salmon sperm DNA/protein G agarose in a $50 \%$ slurry for $60 \mathrm{~min}$ at $4{ }^{\circ} \mathrm{C}$ with agitation. The supernatant was then collected and $10 \mu \mathrm{l}$ mouse monoclonal anti-biotin antibody was added (Sigma). The solution was incubated overnight at $4{ }^{\circ} \mathrm{C}$ with rotation. To collect the antibody/ biotin/RNA/chromatin complex, we used $\mathrm{G}$ agarose beads (Upstate Technology), followed by washing and elution. DNA fragments were recovered by phenol/chloroform extraction and ethanol precipitation in accordance with the standard ChIP protocol described elsewhere (Soejima et al. 2004).

Genomic PCR analysis was performed for detecting LIT1 RNA-accumulated chromatin regions. Primer sequences and PCR conditions are available upon request. Products were visualized by electrophoresis on $2 \%$ agarose gels.

\section{Results}

Visualization of the LITI RNA molecule by FISH

To better understand the profile of the LIT1 non-coding RNA, we attempted FISH to examine the sub-cellular localization of LITI RNA molecules in Chinese hamster ovary (CHO) hybrid cells. As shown in Fig. 1b, human 

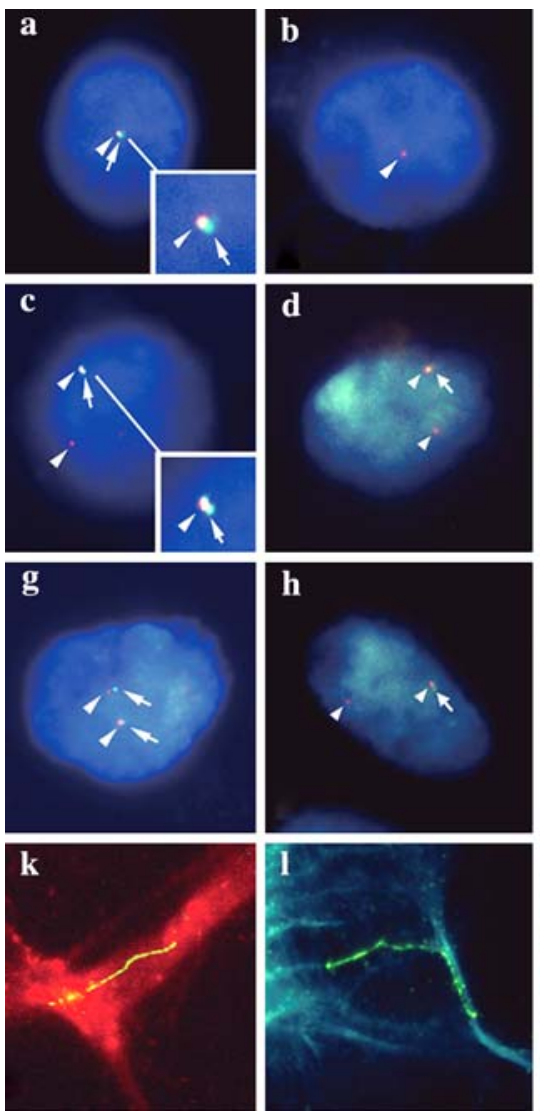

Fig. 2 Expression analysis and sub-cellular localization of LIT1 and UBE3A RNA. Cytogenetic analysis of LIT1 localization by RNA/ DNA fluorescence in situ hybridization (FISH). RNA signals are shown in green (arrow) and DNA signals are shown in red (arrowhead). Interphase nuclei were counterstained with $4^{\prime}, 6^{\prime}$-diamidino-2-phenylindole (DAPI). a-f LIT1 RNA/DNA FISH. LIT1 RNA and DNA signals are detected in CHO11P-8, while only the LIT1 DNA signal is detected in $\mathrm{CHO}_{11} \mathrm{P}^{\Delta \mathrm{CpG}}-10$ (a $\mathrm{CHO} 11 \mathrm{P}-8$, b $\mathrm{CHO} 1 \mathrm{P} \Delta \mathrm{CpG}-10)$. Monoallelic expression of LIT1 is observed in normal human fibroblast (NHF) cell lines. The RNA signal was detected in the vicinity of its DNA signals (c NHF, $\mathbf{d}$ NHF2, e NTI-4,

LIT1 transcripts, but not from the maternally expressed imprinted $K C N Q 1$, were detectable in $\mathrm{CHO}$ hybrid cells that carried a paternal copy of human chromosome 11

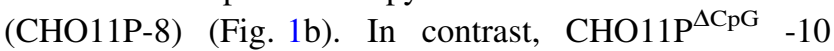
hybrid cells, which contain a modified paternal human chromosome 11 that lacks the LITI CpG island, expressed $K C N Q 1$, presumably due to a loss of LITI function. These results are consistent with the findings of a previous study (Horike et al. 2000).

We used a U90095 PAC that includes the whole sequence of the LITI transcript and which in our case consisted of the majority of intron sequences of $K C N Q 1$ as a FISH probe. We used the same probe in both RNA and DNA FISH. However, because cells were subjected to hybridization under non-denaturing conditions such that cellular DNA was not accessible, we could detect only primary transcripts by RNA FISH (Clemson et al.
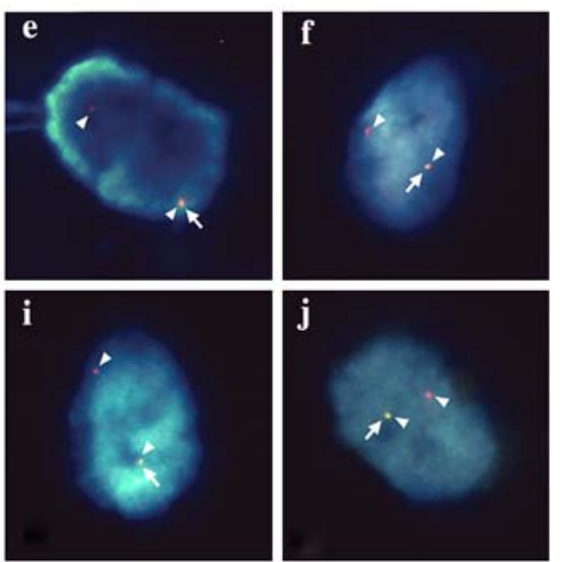

$\mathbf{m}$
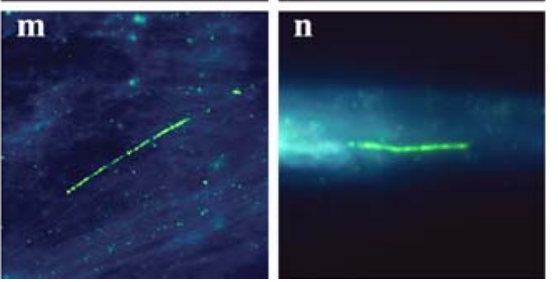

f TIG-1-20). LIT1 RNA stably localizes to the region containing the LIT1 gene in CHO11P-8 and NHFs. g-j UBE3A RNA/DNA FISH. $U B E 3 A$ RNA and DNA are detected in normal human fibroblast cell lines (g NHF, h NHF2, I NTI-4, j TIG-1-20). k-n High-resolution fiber FISH. Chromatin fibers were counterstained with propidium iodide (PI) or DAPI. Coating of the chromatin fiber with the LIT1 RNA is visualized by high-resolution fiber FISH in normal human fibroblast cell lines (k NHF, I NHF2, m NTI-4, n TIG-1-20). LIT1 RNA signal was detected along with chromatin fibers, but not $U B E 3 A$. Results with the NHF are representative of results from normal human lymphoblast cell lines (date not shown)

1996; Van Raamsdonk and Tilghman 2001). We performed RNA FISH followed by DNA FISH on the same samples (RNA/DNA FISH). The RNA/DNA FISH shows that the LITI RNA signal co-localized with DNA in these CHO hybrid interphase nuclei. We detected a single LITI RNA signal in the nuclei of CHO11P-8 hybrid cells; in contrast, the RNA signal was not detected in

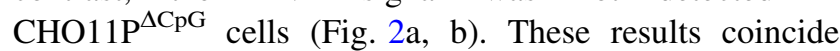
with data from the RT-PCR (Fig. 1b). The LIT1 RNA signal was detected only in nuclei as a single spot, even when PAC (approximately $100 \mathrm{~kb}$ in length) or the $10-\mathrm{kb}$ LIT1 5'-genomic DNA fragment was used as a probe (data not shown). This signal disappeared when the samples were treated with RNase A prior to probe hybridization (data not shown). These results indicate that the U90095 PAC probe was exclusively able to detect LIT1 transcripts but not KCNQ1 transcripts. 
Table 1 Frequency distribution (\%) of the number of spots per cell for $L I T 1$ and $U B E 3 A$
One hundred interphase cells were analyzed

a NHL, Normal human lymphoblast cell line; NHF, NHF2, NTI-4, TIG-1-20, normal human fibroblast cell lines

\begin{tabular}{lllllll}
\hline Imprinting gene & Cell lines & & \multicolumn{2}{l}{ Number of RNA signals } & & \\
\cline { 3 - 7 } & & Zero & One & Two & Three & Four \\
\hline \multirow{2}{*}{ LIT1 } & NHL & 3 & 89 & 7 & 1 & 0 \\
& NHF & 2 & 96 & 2 & 0 & 0 \\
& NHF2 & 9 & 83 & 8 & 0 & 0 \\
& NTI-4 & 6 & 84 & 9 & 1 & 0 \\
& TIG-1-20 & 6 & 82 & 12 & 0 & 0 \\
UBE3A & NHL & 35 & 43 & 20 & 2 & 0 \\
& NHF & 41 & 39 & 15 & 4 & 1 \\
& NHF2 & 39 & 38 & 21 & 2 & 0 \\
& NTI-4 & 39 & 43 & 17 & 1 & 0 \\
& TIG-1-20 & 46 & 35 & 18 & 1 & 0 \\
\hline
\end{tabular}

LIT1 RNA stably co-localizes with its own gene region through the cell cycle

We next performed RNA/DNA FISH on normal human lymphoblasts (NHF) and normal human fibroblasts (NHF, NHF2, NTI-4, TIG-1-20) to confirm the physiological state of LIT1 RNA in human cells (Fig. 2c-f; Table 1). LIT1 RNA signals were observed in almost all interphase nuclei of the lymphoblast cell line (97\% of interphase nuclei) and of four fibroblast cell lines $(98,91,94,94 \%$ of interphase nuclei; Table 1). In these cells, LITI RNA spatially coincided with the LIT1 DNA locus. The distribution of the RNA in both human lymphoblast and fibroblast cell lines was similar to that found in the $\mathrm{CHO}$ hybrid cell. Intriguingly, the RNA signal was detectable in most nuclei, despite the fact that cell cycle was not synchronized.

To evaluate this distinctive feature of non-coding transcript LIT1, we analyzed the RNA FISH signal of UBE3A, an imprinted gene known to exhibit exclusively maternal expression. In contrast to $L I T 1$, the $U B E 3 A$ transcript is translated into protein. The $U B E 3 A$ RNA was visible in only $65 \%$ of the lymphoblast cell line and in only 59,61 , $61,54 \%$ of the four fibroblast cell lines, respectively (Fig. 2g-j; Table 1).

Using DNA/RNA FISH, we detected intronless noncoding LIT1 RNA signals in most nuclei, which is in sharp contrast to UBE3A RNA signals, and did not detect LIT1 RNA signals in the cytoplasm. These results strongly suggest that LIT1 transcripts stably co-localize with its own gene region as non-coding RNA throughout the cell cycle and, in contrast to $U B E 3 A$ transcripts, exhibit tissue-specific imprinted expression (Kagotani et al. 2002). These results therefore support the idea that LIT1 acts as a functional RNA in the nucleus (Kanduri et al. 2006; Mancini-Dinardo et al. 2006) and that the co-localization of the LITI RNA molecule to the LIT1 locus may represent mature and functional RNA molecules, rather than simply nascent transcripts.
LIT1 RNA accumulates on chromatin

To date, nine different non-coding RNAs associated with epigenetic gene regulation (including genomic imprinting and $X$ chromosome inactivation) at single gene loci, subchromosomal regions or chromosomal regions have been found in mice and humans (Heard and Disteche 2006; Jong et al. 1999; Lee et al. 2000; Lin et al. 2003; Rougeulle et al. 1998; Sleutels et al. 2002; Wroe et al. 2000). Of these, the non-coding XIST RNA has been particularly well characterized. XIST RNA is known to act as a regulatory molecule in $X$ chromosome inactivation, which accomplishes dosage compensation in mammals. XIST RNA coats and spreads along the $X$ chromosome, recruits the silencing complexes, including histone methyltransferase and the polycomb group proteins Eed/Ezh2/Suz12, and eventually establishes $X$ chromosome inactivation by inducing heterochromatin formation and DNA methylation (Heard and Disteche 2006).

It has recently been suggested that gene regulation by Litl RNA is accompanied by histone modifications (mono-, di-, triMe-H3K9 and triMe-H3K27) and that DNA methylation in specific regions and the existence of the Lit1 RNA is important for these regulatory systems (Kanduri et al. 2006; Soejima et al. 2004). Together with our previous our experimental data (Horike et al. 2000; Mitsuya et al. 1999), our findings suggest that LIT1 transcripts may act by coating the subchromosomal region in a way that resembles $\mathrm{X}$ chromosome inactivation.

To test this theory, we used high-resolution fiber FISH, which allows the visualization of small DNA elements on subchromosomal regions, to analyze LIT1 transcript localization (Parra and Windle 1993). Interestingly, the accumulation of LIT1 RNA signals, but not UBE3A signals, was observed on chromatin fibers prepared from a normal human fibroblast cell line (Fig. 2k-n; data not shown). Our results suggest that prolonged association of LIT1 RNA with chromatin may be significant for transcriptional silencing of the imprinted gene clusters. 
Identification of the LIT1 RNA spread region by modified RNA TRAP analysis

To determine the precise region over which LIT1 RNA spreads, we performed DNA FISH after fiber RNA FISH. However, we did not detect any DNA signal. The fiber DNA was very weak, and the RNA signal on the DNA fiber was detected throughout many complex processes that involved washing by FISH. As a result, fiber DNA was lost due to these additional DNA FISH processes, i.e. denaturing and washing. We then developed a modified RNA TRAP analysis combined with RNA FISH and ChIP analysis to study the single strand RNA-DNA interactions on chromatin in situ (Carter et al. 2002). Following RNA in situ hybridization using a biotin-labeled U90095 PAC probe, crosslinked chromatin was isolated by immunoprecipitation with an antibody recognizing biotin. The DNA sample prepared from these complexes was analyzed in a number of imprinted gene regions by PCR analysis to determine whether the DNA sample contained regions outside of the LIT1 domain. We confirmed the expression profiles (RT-PCR and RNA FISH) of some imprinted genes containing LIT1 in normal human fibroblast cell lines (Table 1; Fig. 3a). We then attempted the modified RNA TRAP method. Intriguingly, PCR products showing the presence of LITI RNA were found on CDKNIC and
IMPT1, both of which lie outside of the LIT1 RNA transcriptional domain in normal human fibroblasts. The LITI RNA was not detected on $I G F$, indicating that the distal border lies between the LIT1 and the IGF2 (Fig. 3b, c). However, the accumulation of LIT1 RNA on IPL region was not reproducible. We are not able to identify the proximal boundary region at this time, and the results suggest that a better method is required for the identification of the proximal boundary region.

These results suggest that LITI transcripts may regulate gene expression by coating the subchromosomal region in a way that resembles $X$ chromosome inactivation by XIST RNA. The unique behavior of LITI RNA may contribute to the establishment of parental-specific expression within an imprinted cluster. Thus, functional non-coding RNAs may play important roles in modulating transcription at specific chromatin domains (Horike et al. 2000; Kanduri et al. 2006; Mancini-Dinardo et al. 2006).

\section{Discussion}

In an attempt to elucidate the regulatory mechanism of the human 11p15.5 imprinting domain by LIT1 non-coding RNA, we performed LIT1 DNA/RNA FISH, fiber RNA FISH and the modified RNA TRAP method using CHO
Fig. 3 Analysis of regions in which LIT1 RNA accumulates using a modified RNA tagging and recovery of associated proteins (TRAP) method. a Expression analysis of imprinted genes in NHFs by reverse transcriptase-PCR. b Schematic representation of the primers used for the modified RNA TRAP method. Red boxes indicate maternally expressed genes and blue boxes indicate paternally expressed genes. c Accumulation of LIT1 RNAs on the IMPT1 region, $\mathrm{KC} 1, \mathrm{KC} 2$ and $\mathrm{LC} 1$ on the $C D K N 1 C$ region and $\mathrm{LC} 2, \mathrm{LC} 3$ on the LIT1 and IGF2 regions. PCR was performed using DNAs extracted from input (lane 1), antibody (lane 2) and no antibody (lane 3) preparations. Modified RNA TRAP analysis was performed independently three times. Primer sequences and PCR conditions are available upon request

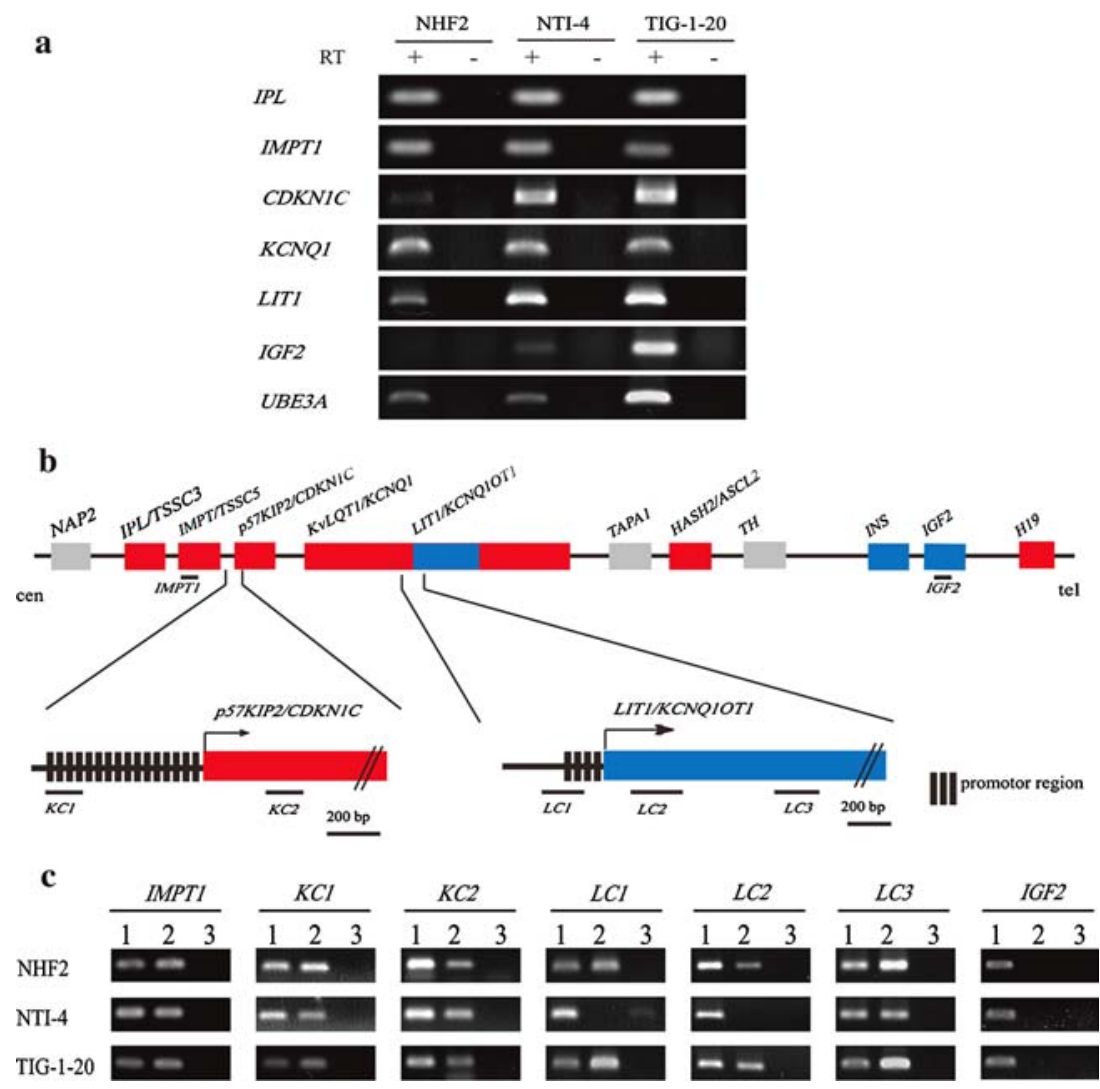


hybrid, NHL and NHF cells. Intriguingly, we observed that LIT1 RNA stably accumulated on its own gene region and that the $S L C 22 A 18 / I M P T 1$ and $C D K N 1 C / p 57 K I P 2$ regions, which lie outside of the LITI RNA transcriptional domain, accumulated through the cell cycle. These data suggest that LITI RNA may play a significant role in modulating transcription at specific chromosome domains, such as IC.

Kagotani et al. (2002) reported that they detected RNA signals in some imprinted and non-imprinted genes that contain $U B E 3 A$ in more than $80 \%$ of the interphase nuclei of human lymphoblastoid cells and mouse embryo fibroblast cells. We currently cannot explain this large discrepancy in the frequency of UBE3A RNA signal reported by Kagotani et al. and our data, but this question will be solved in future investigations carried out on control of the cell cycle.

To detect the UBE3A RNA signal, we used a cosmid probe (cosmid 16) that consists of the majority of intron sequences on UBE3A-ATS (Meguro et al. 2001; Runte et al. 2001). Therefore, it dominantly detected UBE3A transcripts in human fibroblast cell lines but not UBE3A-ATS transcripts. A PAC probe (U90095) that contains intron sequences on $K v L Q T 1$, exclusively detected LITI transcripts in our study. Furthermore, if a cosmid probe were to detect UBE3A-ATS nascent RNA, U90095 should be also be detected at nascent RNA of antisense KvLQT1. However, U90095 detected only LIT1 transcripts.

The LIT1 RNA was detected at the LC1 and LC2 regions in NHF2 and TIG-1-20 cells, but not in NTI-4 cells. It is possible that this accumulation to genes of the LITI RNA may significantly affect the expression of a specific region rather than the overall length of a gene for transcriptional regulation. Another possible mechanism is the different strength of the coating in genes. Further analysis of LITI region in various cells is required to resolve the issue.

The well-known non-coding RNA, Xist, triggers XCI by accumulation along the whole $X$ chromosome. The triggering of XCI is accompanied by DNA methylation and histone modification. The polycomb complex (PRC), BRCA1 and HP1 are also associated with the inactive $X$ chromosome. These factors are essential for XCI activation. It has recently been suggested that DNA methylation and histone modification are also important for the LITI RNA regulatory mechanisms. By analogy with Xist RNA, it is feasible that the XCI and LITI RNA regulatory mechanisms share same factors. We are currently attempting to isolate these factors that interact with the LIT1 RNA accumulated regions.

The Lit1 RNA has been reported to regulate placentaspecific imprinted genes expression, including Osbpl5, Tssc4, Cd81 and ASCL2, in mammalian early development. It has also been suggested that the timing of LITl RNA expression is important for the proper initiation of these genes (Annabelle Lewis et al. 2006; Kelly Green et al. 2007). We used differentiated human fibroblasts for the RNA TRAP methods. One interesting result was that the LIT1 RNA was detected in only the ubiquitously imprinted gene regions but not in placenta-specific imprinting gene regions (date not shown). Future studies of LITI RNA function should focus on whether LITI RNA accumulates in placenta-specific imprinted gene regions during the early development stages that establish the placental specific imprinting.

The mechanism by which LITI RNA accumulation contributes to the transcriptional silencing of imprinted gene clusters is still unknown. Therefore, it will be important to focus future studies on functional sequences within LITI RNA and on proteins that bind to non-coding RNAs in order to better understand how non-coding RNAs bring about epigenetic gene regulation at imprinted gene clusters.

Acknowledgements We thank Dr. Andrew P. Feinberg (Johns Hopkins University School of Medicine) for the kind of gift of the U90095 PAC. This work was supported in part by grants from the Ministry of Health, Labour and Welfare and from the Ministry of Education, Culture, Sports, Science and Technology of Japan.

\section{References}

Bliek J, Maas SM, Ruijter JM, Hennekam RC, Alders M, Westerveld A, Mannens MM (2001) Increased tumour risk for BWS patients correlates with aberrant $H 19$ and not KCNQ1OT1 methylation: occurrence of KCNQ1OT1 hypomethylation in familial cases of BWS. Hum Mol Genet 10:467-476

Carter D, Chakalova L, Osborne CS, Dai YF, Fraser P (2002) Longrange chromatin regulatory interactions in vivo. Nat Genet 32:623-626

Clemson CM, McNeil JA, Willard HF, Lawrence JB (1996) XIST RNA paints the inactive $X$ chromosome at interphase: evidence for a novel RNA involved in nuclear/chromosome structure. J Cell Biol 132:259-275

Delaval K, Feil R (2004) Epigenetic regulation of mammalian genomic imprinting. Curr Opin Genet Dev 14:188-195

Fitzpatrick GV, Soloway PD, Higgins MJ (2002) Regional loss of imprinting and growth deficiency in mice with a targeted deletion of KvDMR1. Nat Genet 32:426-431

Green K, Lewis A, Dawson C, Dean W, Reinhart B, Chaillet JR, Reik W (2007) A developmental window of opportunity for imprinted gene silencing mediated by DNA methylation and the Kcnq1ot1 noncoding RNA. Mammal Genome 18:32-42

Heard E, Disteche CM (2006) Dosage compensation in mammals: fine-tuning the expression of the $\mathrm{X}$ chromosome. Genes Dev 20:1848-1867

Herzing LB, Cook EH, Ledbetter DH (2002) Allele-specific expression analysis by RNA-FISH demonstrates preferential maternal expression of $U B E 3 A$ and imprint maintenance within 15q11-q13 duplications. Hum Mol Genet 11:1707-1718

Horike S, Mitsuya K, Meguro M, Kotobuki N, Kashiwagi A, Notsu T, Schulz TC, Shirayoshi Y, Oshimura M (2000) Targeted disruption of the human LIT1 locus defines a putative imprinting 
control element playing an essential role in Beckwith-Wiedemann syndrome. Hum Mol Genet 9:2075-2083

Jong MT, Gray TA, Ji Y, Glenn CC, Saitoh S, Driscoll DJ, Nicholls RD (1999) A novel imprinted gene, encoding a RING zinc-finger protein, and overlapping antisense transcript in the Prader-Willi syndrome critical region. Hum Mol Genet 8:783-793

Kagotani K, Nabeshima H, Kohda A, Nakao M, Taguchi H, Okumura K (2002) Visualization of transcription-dependent association of imprinted genes with the nuclear matrix. Exp Cell Res 274:189-196

Kanduri C, Thakur N, Pandey RR (2006) The length of the transcript encoded from the Kcnq1ot 1 antisense promoter determines the degree of silencing. EMBO J 25:2096-2106

Lee MP, DeBaun MR, Mitsuya K, Galonek HL, Brandenburg S, Oshimura M, Feinberg AP (1999) Loss of imprinting of a paternally expressed transcript, with antisense orientation to $K V L Q T 1$, occurs frequently in Beckwith-Wiedemann syndrome and is independent of insulin-like growth factor II imprinting. Proc Natl Acad Sci USA 96:5203-5208

Lee YJ, Park CW, Hahn Y, Park J, Lee J, Yun JH, Hyun B, Chung JH (2000) Mit1/Lb9 and Copg2, new members of mouse imprinted genes closely linked to Peg1/Mest(1). FEBS Lett 472:230-234

Lewis A, Green K, Dawson C, Redrup L, Huynh KD, Lee JT, Hemberger M, Reik W (2006) Epigenetic dynamics of the Kcnq1 imprinted domain in the early embryo. Development 133:4203-4210

Lin SP, Youngson N, Takada S, Seitz H, Reik W, Paulsen M, Cavaille J, Ferguson-Smith AC (2003) Asymmetric regulation of imprinting on the maternal and paternal chromosomes at the Dlk1-Gtl2 imprinted cluster on mouse chromosome 12. Nat Genet 35:97-102

Mancini-Dinardo D, Steele SJ, Levorse JM, Ingram RS, Tilghman SM (2006) Elongation of the Kcnqlot1 transcript is required for genomic imprinting of neighboring genes. Genes Dev 20:12681282

Meguro M, Mitsuya K, Nomura N, Kohda M, Kashiwagi A, Nishigaki R, Yoshioka H, Nakao M, Oishi M, Oshimura M (2001) Largescale evaluation of imprinting status in the Prader-Willi syndrome region: an imprinted direct repeat cluster resembling small nucleolar RNA genes. Hum Mol Genet 10:383-394

Mitsuya K, Meguro M, Lee MP, Katoh M, Schulz TC, Kugoh H, Yoshida MA, Niikawa N, Feinberg AP, Oshimura M (1999) LIT1, an imprinted antisense RNA in the human KvLQT1 locus identified by screening for differentially expressed transcripts using monochromosomal hybrids. Hum Mol Genet 8:1209-1217
Nakano S, Murakami K, Meguro M, Soejima H, Higashimoto K, Urano T, Kugoh H, Mukai T, Ikeguchi M, Oshimura M (2006) Expression profile of $L I T 1 / K C N Q 1 O T 1$ and epigenetic status at the KvDMR1 in colorectal cancers. Cancer Sci 97:1147-1154

Parra I, Windle B (1993) High resolution visual mapping of stretched DNA by fluorescent hybridization. Nat Genet 5:17-21

Rougeulle C, Cardoso C, Fontes M, Colleaux L, Lalande M (1998) An imprinted antisense RNA overlaps $U B E 3 A$ and a second maternally expressed transcript. Nat Genet 19:15-16

Runte M, Huttenhofer A, Gross S, Kiefmann M, Horsthemke B, Buiting K (2001) The IC-SNURF-SNRPN transcript serves as a host for multiple small nucleolar RNA species and as an antisense RNA for UBE3A. Hum Mol Genet 10:2687-2700

Scelfo RA, Schwienbacher C, Veronese A, Gramantieri L, Bolondi L, Querzoli P, Nenci I, Calin GA, Angioni A, Barbanti-Brodano G, Negrini M (2002) Loss of methylation at chromosome 11p15.5 is common in human adult tumors. Oncogene 21:2564-2572

Schwienbacher C, Gramantieri L, Scelfo R, Veronese A, Calin GA, Bolondi L, Croce CM, Barbanti-Brodano G, Negrini M (2000) Gain of imprinting at chromosome 11p15: a pathogenetic mechanism identified in human hepatocarcinomas. Proc Natl Acad Sci USA 97:5445-5449

Sleutels F, Zwart R, Barlow DP (2002) The non-coding Air RNA is required for silencing autosomal imprinted genes. Nature 415:810-813

Soejima H, Nakagawachi T, Zhao W, Higashimoto K, Urano T, Matsukura S, Kitajima Y, Takeuchi M, Nakayama M, Oshimura M, Miyazaki K, Joh K, Mukai T (2004) Silencing of imprinted $C D K N 1 C$ gene expression is associated with loss of $\mathrm{CpG}$ and histone H3 lysine 9 methylation at DMR-LIT1 in esophageal cancer. Oncogene 23:4380-4388

Surani MA, Barton SC, Norris ML (1986) Nuclear transplantation in the mouse: heritable differences between parental genomes after activation of the embryonic genome. Cell 45:127-136

Tanaka K, Shiota G, Meguro M, Mitsuya K, Oshimura M, Kawasaki $\mathrm{H}$ (2001) Loss of imprinting of long $Q T$ intronic transcript 1 in colorectal cancer. Oncology 60:268-273

Van Raamsdonk CD, Tilghman SM (2001) Optimizing the detection of nascent transcripts by RNA fluorescence in situ hybridization. Nucleic Acids Res 29:E42

Wroe SF, Kelsey G, Skinner JA, Bodle D, Ball ST, Beechey CV, Peters J, Williamson CM (2000) An imprinted transcript, antisense to Nesp, adds complexity to the cluster of imprinted genes at the mouse Gnas locus. Proc Natl Acad Sci USA 97:3342-3346 